Department of Pediatrics and Child Health, University of Manitoba, IM-PACT: Injuries

Manitoba-Prevention of Adolescent and Childhood Trauma, Winnipeg, Manitoba, Canada

L Warda

M E K Moffatt

Department of Pediatrics and Child Health, University of Manitoba

M Tenenbein

Correspondence to: Dr L Warda, 840 Sherbrook Street, Room CN 104, Winnipeg, Manitoba, R3A 1S1, Canada (e-mail: lwarda@escape.ca).

\title{
House fire injury prevention update. Part II. A review of the effectiveness of preventive interventions
}

\author{
Lynne Warda, Milton Tenenbein, Michael E K Moffatt
}

\begin{abstract}
Objective-To evaluate and summarize the house fire injury prevention literature.

Methods-MEDLINE (1983 to March 1997) was searched by keyword: fire, burn, etiology, cause, prevention, epidemiology, and smoke detector/alarm. ERIC (1966 to March 1997) and PSYCLIT (1974 to June 1997) were searched by keyword: as above, and safety, skills, education, and training. Other sources included references of retrieved publications, review articles, and books; Injury Prevention hand search; government documents; and internet sources. Sources relevant to residential fire injury prevention were selected, evaluated, and summarized.

Results-Forty three publications were selected for review, including seven randomized controlled trials, nine quasiexperiments, two natural experiments, 21 prospective cohort studies, two cross sectional surveys, one case report, and one program evaluation. These studies examined the following types of interventions: school (9), preschool (1), and community based educational programs (5); fire response training programs for children (7), blind adolescents (2), and mentally retarded adults (5) and children (1); office based counseling (4); home inspection programs (3); smoke detector giveaway campaigns (5); and smoke detector legislation (1).

Conclusions-This review of house fire prevention interventions underscores the importance of program evaluation. There is a need for more rigorous evaluation of educational programs, particularly those targeted at schools. An evidence based, coordinated approach to house fire injury prevention is critical, given current financial constraints and the potential for program overload for communities and schools.

(Injury Prevention 1999;5:217-225)
\end{abstract}

Keywords: fire prevention; fire epidemiology; smoke detectors; residential fires
Numerous house fire prevention initiatives have been introduced in many communities around the world in an attempt to reduce house fire morbidity and mortality. These measures have included education and training of children, parents, and certain high risk populations such as the elderly, in both school and community based programs ${ }^{1-4}$; promotion of smoke detectors and sprinkler systems for home use, as well as smoke detector legislation $^{5-7}$; introduction of flame retardant fabrics and clothing, and related industry standards and regulations ${ }^{8}{ }^{9}$; and recent innovations such as the development of the so-called "fire safe" cigarette.$^{10-15}$ However, the effectiveness of many of these methods in reducing house fire injuries and deaths is unknown. Educational programs in particular are widespread, but their relative effectiveness has not been established. Of the many available programs, in which should a community or a school invest time and financial resources? The literature lacks a summary of this diverse research; therefore this review was initiated to evaluate and summarize the evidence for house fire injury prevention interventions.

\section{Methods}

LITERATURE REVIEW

The literature review methods are described in part I of this series. ${ }^{16}$

\section{DATA ANALYSIS}

All publications evaluating an intervention that could reduce house fire death or injury were included. For example, an educational program teaching children to "stop, drop, and roll" would be included, because this skill could be applied to fires at home as well as to fires in other locations. The following data were abstracted from each publication: study period; location of study, including country and type of population examined, such as school, city, county, state, or country; study design and unit of analysis, such as individual, or household; subject and data sources; sample size for each study group; and relevant results. Study designs were classified using principles outlined by Abramson. ${ }^{17}$

For ease of comparison, study data were organized by outcome category and then by 
type of intervention. Outcome categories included house fire morbidity and mortality, smoke detector use and function, fire and burn prevention knowledge, and fire and burn prevention behaviors. Types of interventions were determined by the scope of the retrieved publications, and included categories such as educational programs, smoke detector giveaway campaigns, and office based counseling. Within each outcome category, studies were grouped by type of intervention, and then by level of evidence, in descending order of strength: randomized controlled trial, quasiexperiment, natural experiment, cohort, cross sectional survey, and case report. After ranking by level of evidence, studies were then ordered by degree of validity, from most valid to least valid, as previously described. The final ranking of studies is reflected in the order in which the studies appear in the tables.

\section{Results}

Forty three publications were selected for review, including seven randomized controlled trials, nine quasiexperiments, two natural experiments, 21 prospective cohort studies, two cross sectional surveys, one case report, and one program evaluation. These studies examined the following types of interventions: school (9), preschool (1), and community based educational programs (5); fire response training programs for children (7), blind adolescents (2), mentally retarded adults (5) and children (1); office based counseling (4); home inspection programs (3); smoke detector giveaway campaigns (5); and smoke detector legislation (1).

INTERVENTION STUDIES MEASURING FIRE AND BURN PREVENTION KNOWLEDGE

The 14 intervention studies measuring fire and burn prevention knowledge are summarized in table 1 . These interventions include numerous school based educational efforts, with both long term ${ }^{4819}$ and short term ${ }^{20-25}$ programming and evaluation components; a preschool educational program ${ }^{26}$; community based educational programs for seniors ${ }^{22}$ and new residents of public housing ${ }^{27}$; a fire response training program for mentally retarded adults ${ }^{28}$; and pediatric office based counseling. ${ }^{29}$ Short term outcome evaluation and lack of rigorous evaluation limit the majority of these studies.

Three studies of large scale school based educational interventions have been reported. The most recent study examined a program for elementary students introduced by the New Zealand Fire Service. ${ }^{18}{ }^{19}$ Firefighters taught and demonstrated fire safety concepts, with a different module for each of three levels of primary students. Although baseline knowledge level was high, there was some improvement in children's knowledge after the program had been in place three years. Involvement by schools in the program was variable, however, with $20 \%-70 \%$ of schools reporting participation in all three components between 1992 and 1995. This may have limited the effectiveness of the program.
Project Burn Prevention examined an eight month educational program introduced in 22 public elementary schools and three high schools in an urban community. ${ }^{3}$ Three grade levels were targeted: kindergarten and grade 1 , grades 2 and 3, and grades 10 to 12 . Post-test scores were significantly higher in the intervention community than in a similar control community. The only other study of a large scale school based educational intervention examined the effectiveness of the Learn Not To Burn (LNTB) curriculum in grade 3 and 4 students. ${ }^{4}$ This study used a random sample of schools stratified by location in the state, urban-rural status, and LNTB participation status. Students were pre-tested and posttested using the standardized LNTB test. Pretest and post-test scores did not differ between children attending schools using the LNTB curriculum and those attending schools with other fire safety programs or with no established program.

A number of studies have examined smaller scale educational efforts, such as puppet shows $^{20}$ and short multimedia educational presentations..$^{21-25}$ Though well received by their audiences, long term maintenance of knowledge and skills is limited with a single intervention, and the majority of these studies did not test knowledge retention beyond two weeks. These programs, however, could be integrated into larger scale projects.

A successful community based training program targeted heads of households who were new tenants in housing projects administered by the Memphis Housing Authority (MHA). ${ }^{27}$ Although smoke detectors were located in every residence, a 1992 baseline spot check of 325 units revealed that $92 \%$ had been vandalized or were otherwise inoperable. The training program consisted of a lecture and video with MHA footage and a dramatization of a child being carried out of a smoke filled building by a firefighter. After the presentation, each trainee signed a commitment sheet that indicated at least three fire safety behaviors they would try to achieve, and each was given a large card with five key fire safety behaviors to display in their home as a reminder. The training sessions were very well received by new residents. Pre-tests and post-tests demonstrated significant increases in knowledge, and trainee households had a lower incidence of fires than untrained households (see tables 1 and 2).

Many of these studies are directly relevant to the development of school based educational programs. They highlight a number of issues that would be of interest to program developers, such as specific program successes, and difficulties encountered in implementation. Several studies used age appropriate tests, for example, picture tests for younger grades, ${ }^{322}$ and many of the projects demonstrated imaginative and multidisciplinary approaches. A number of weaknesses limit these studies, however: questionnaires were rarely validated; pre-tests and post-tests were not administered in a controlled manner ${ }^{4} 181^{21-25}$; most studies administered post-tests too soon after the 

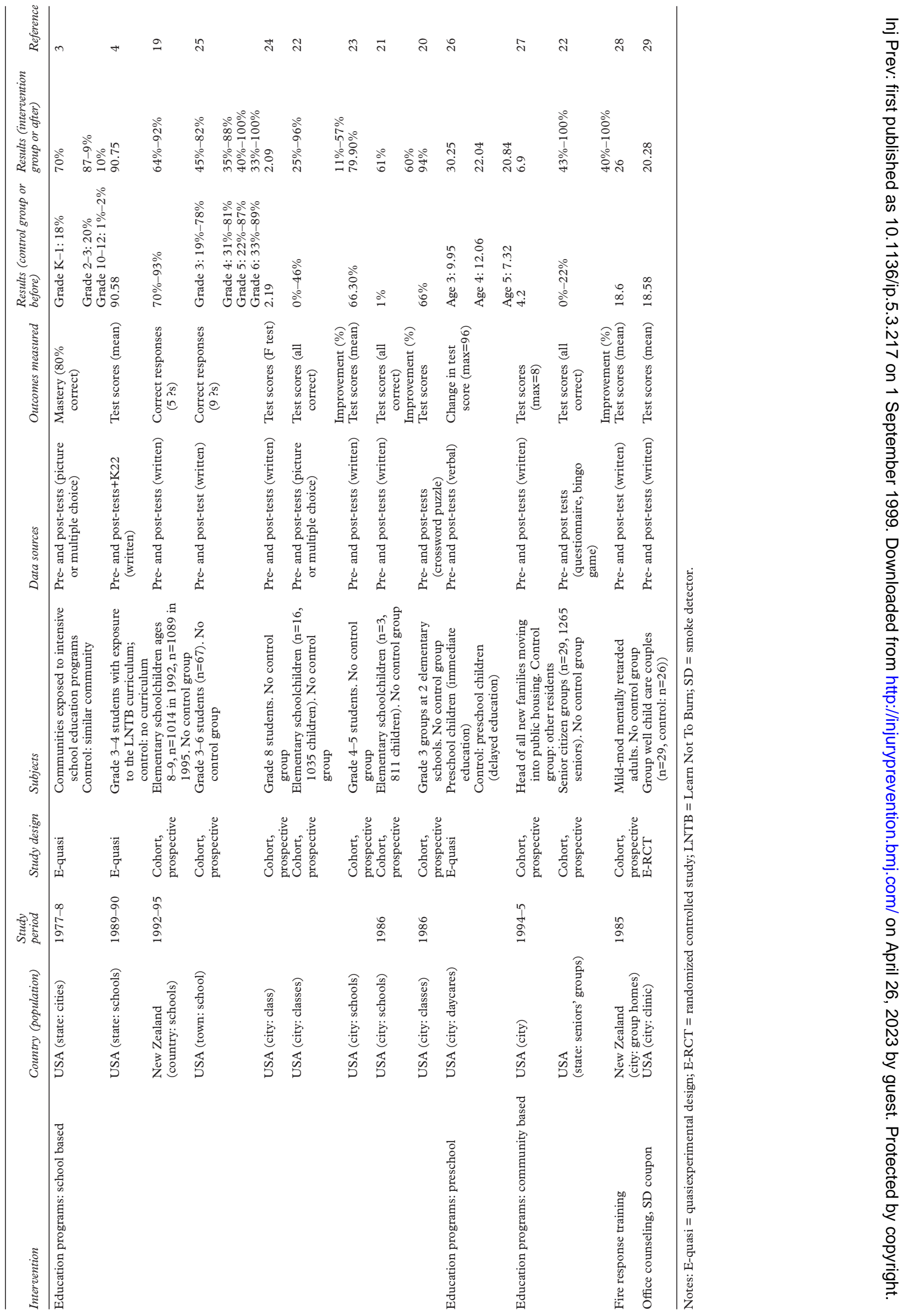

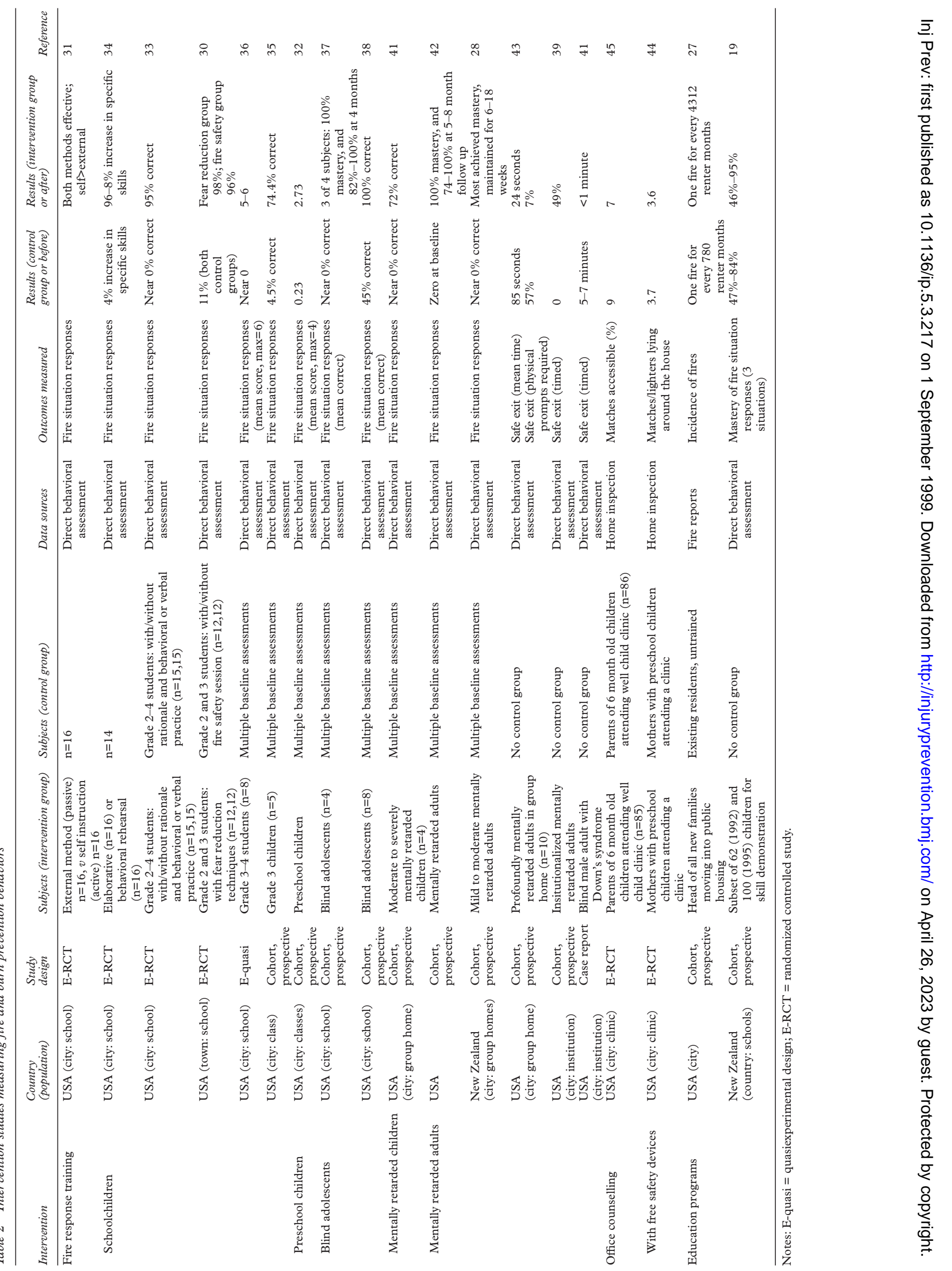
intervention, often less than one week, with no subsequent follow up ${ }^{20-25}$; most studies used convenience samples, with no control for confounding variables ${ }^{20-25}$; and few used a control group for comparison.

INTERVENTION STUDIES MEASURING FIRE

PREVENTION AND RESPONSE BEHAVIORS

The 19 studies examining fire prevention and response behaviors are summarized in table 2 . These studies included training programs for high risk populations, including children, ${ }^{30-36}$ blind adolescents, ${ }^{37} 38$ and mentally retarded children and adults ${ }^{28}{ }^{39-43}$; a school based educational program ${ }^{18}{ }^{19}$; and a community based training program for new public housing residents. ${ }^{27}$ Included in this series of studies are two randomized controlled trials examining the effectiveness of counseling mothers to reduce household hazards, such as exposed matches and lighters. ${ }^{44}{ }^{45}$ This is a group of well designed, carefully controlled studies, the majority of which were found in the psychology literature. The four randomized controlled trials involving schoolchildren were of equal validity, each having adequately addressed the four types of bias.

The largest school based study was the New Zealand Fire Service program, ${ }^{19}$ in which a subset of children were tested by demonstration of response to three fire situations: clothes on fire, room full of smoke, and telephoning for help. This study documented a significant increase in skills in two of the three situations following the program.

There are a number of rigorous small scale studies involving training of children and other high risk populations in fire response behaviors. These studies are characterized by small group (for example four children) or individualized intensive training, and rehearsal of correct behavioral responses to a variety of fire stimuli, using a standardized simulated bedroom or actual sleeping areas. ${ }^{30-3641}$ In one study, passive (external instruction) and active (self instruction) methods of training were equally effective. Both methods used behavioral rehearsal with active participation by the children. ${ }^{31}$ A number of follow up studies further explored these findings. In one of these, behavioral practice was only slightly more effective than verbal practice in skill acquisition, although all subjects were trained and tested with behavioral scenarios. ${ }^{33}$

Several studies have examined methods to reduce children's fear of fire, with the hypothesis that performance should be improved with fear reduction. Elaborative rehearsal, in which students are taught the rationale behind fire procedures during practice sessions, was more effective than simple behavioral rehearsal in reducing children's fear of fire. ${ }^{34}$ Students taught the rationale behind fire procedures also retained their skills longer than control students, ${ }^{33}$ but both techniques were equally effective in teaching fire situation responses. ${ }^{34}$ A later study used self instructional methods and added fear reduction techniques to one of two experimental groups. Although both experimental groups demonstrated significantly superior behavioral responses than two control groups immediately after the training period, the fear reduction group retained these skills longer. ${ }^{30}$ Even in these intensive training programs, however, loss of skills was marked over time. $^{303133}$

Several studies of mentally retarded children and adults have documented mastery of safe fire exit and self extinguishing procedures in mildly to profoundly affected individuals using a one-to-one or small group approach and behavior modification techniques. ${ }^{28}{ }^{39-43}$ Maintenance of skills was variable, with good retention at 3-8 months. However these studies consistently document the importance of follow up testing and supplementary training..$^{28} 394142$

Office based educational programs for mothers using individualized and interactive approaches have been variably successful in reducing fire and other hazards in the home. One such intervention did not reduce the number of household hazards observed by a home visitor, ${ }^{44}$ but another similar intervention resulted in a modest reduction. ${ }^{45}$

This group of studies is superior to the previous group, due to improved study design and rigor. They document the effectiveness of active participation in learning specific behavioral responses to a variety of fire situations. These life saving skills are directly applicable to real fire situations children might encounter. Although responses to actual situations cannot be tested, many of these studies tested children in simulated and actual bedrooms. These training methods would be more difficult to implement in larger groups, such as classrooms, due to time and cost restraints.

INTERVENTION STUDIES MEASURING SMOKE DETECTOR USE AND FUNCTION

The 10 intervention studies measuring smoke detector use and function are summarized in table 3. These studies represent a wide range of interventions: home inspection with educational intervention ${ }^{46-48}$; screening of home care patient households with provision of smoke detector when required ${ }^{49}$; pediatric office based counseling ${ }^{29}{ }^{45}{ }^{50}$; city-wide ${ }^{51}$ and targeted $^{5}$ smoke detector giveaway programs; and smoke detector legislation. ${ }^{52}$ This group of studies includes six randomized or quasiexperimental designs, and many rated above average in terms of study validity.

Several urban smoke detector giveaway campaigns have been successful in encouraging the installation of smoke detectors, particularly in high risk urban areas. ${ }^{51}$ In one program, follow up home inspections at 4-9 months demonstrated that $81 \%$ of homes having received a smoke detector had an installed and operational detector at follow up. ${ }^{51}$ Although there are also a number of giveaway programs underway in rural areas of the United States, their outcomes have not been published (www.cdc.gov/ncipc/res-opps/firecop2.htm).

The effect of legislation was examined in a study of smoke detector use in a county with a "retrofit" law requiring smoke detector in all homes regardless of the age of the home, 


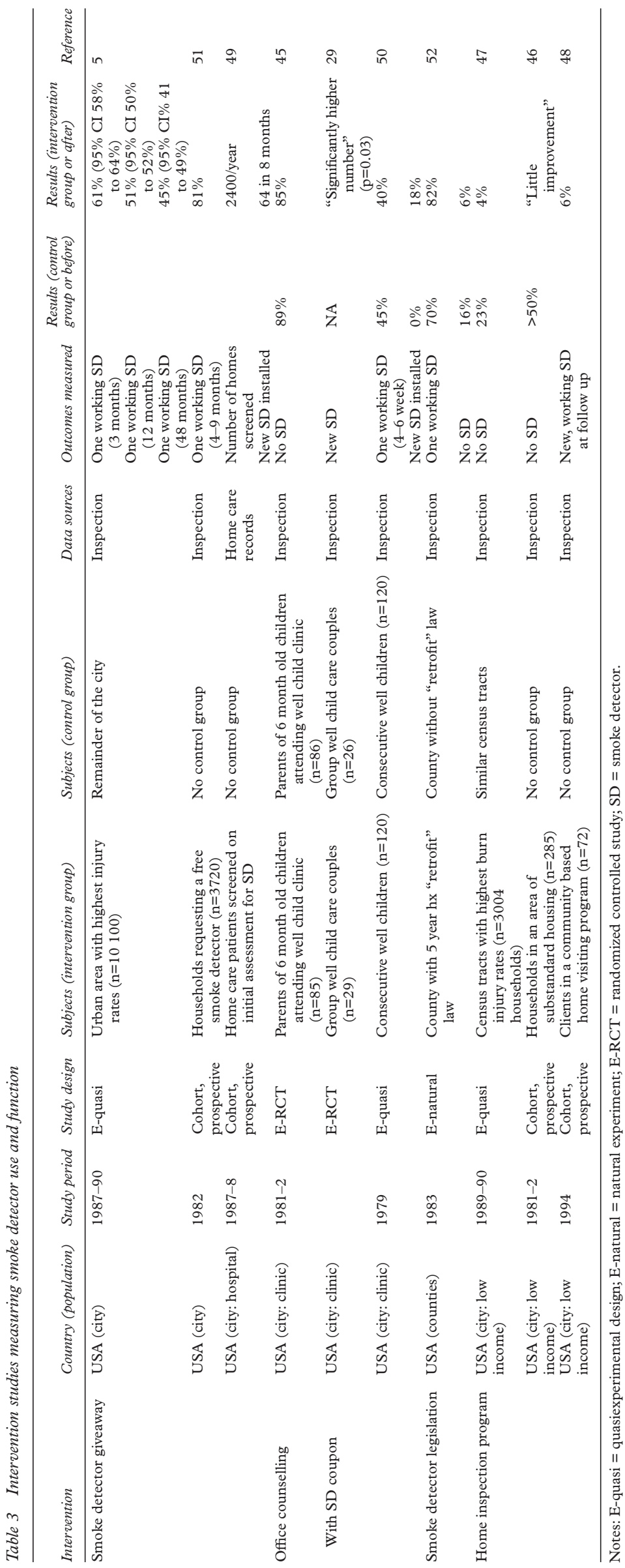

compared with a nearby county with legislation requiring smoke detectors in new homes only. ${ }^{52}$ Homes in the county with the "retrofit" law were less likely to have no operational detector $(17 \%$ v $30 \%)$ and to have no detector at all $(6 \%$ $v 16 \%)$.

Two smaller scale studies deserve mention for their simplicity, success, and innovation. In one, a brief pediatric office counseling intervention, a one minute educational message, pamphlet, and an offer to purchase a smoke detector at cost was effective in encouraging its purchase and installation. Of the 55 families in the experimental group having no smoke detector at the office visit, 26 purchased one within six weeks, compared with none of the control group..$^{50}$ In the second, an innovative burn prevention program was developed for home care patients in which visiting nurses screened households for smoke detectors. Smoke detectors were provided when required, either free or at cost, and installation was verified by the visiting nurse.

The strengths of this group of studies include successful inspection of a large, random sample of households, ${ }^{5152}$ documentation of smoke detector use by home inspection rather than self report, ${ }^{56} 4750-52$ and documentation of smoke detector function by actual testing. ${ }^{5750-52}$ Limitations of these studies include selection of a middle class or affluent sample, ${ }^{50} 52$ and use of non-random allocation. ${ }^{47} 50$

INTERVENTION STUDIES MEASURING RESIDENTIAL FIRE INJURY

The four intervention studies measuring fatal and non-fatal house fire injury are summarized in table 4. This group of studies includes: targeted smoke detector giveaway campaigns $^{5}{ }^{53}$; a large scale community based and school based educational campaign ${ }^{54}$; and an analysis of burn morbidity and mortality trends coincident with community based burn prevention measures. ${ }^{55}$

Studies of fire and burn prevention interventions have reported variable success in reducing fire injury. Residential fire injuries decreased in a high risk urban area after a large scale smoke detector giveaway campaign targeting this area. Fire injury rates decreased by $80 \%$ and injury rates per 100 fires decreased by $74 \%$ in the target area during a four year period after the campaign, whereas the corresponding rates increased slightly in the rest of the city. ${ }^{5}$ Neither the incidence nor the severity of burn injuries reduced during the 12 month period after Project Burn Prevention, a large scale burn prevention campaign with both school and community components. $^{54}$ (Note: McLoughlin et $a \beta^{\beta}$ and MacKay and Rothman ${ }^{54}$ both describe Project Burn Prevention results.) Burn incidence reduced by 3\% per year at a burn unit in Denmark over a 17 year period during which numerous burn prevention measures were initiated, including an extensive media campaign, and product and legislative changes. ${ }^{55}$

These studies measured much needed injury related outcomes. Such studies are infrequently 


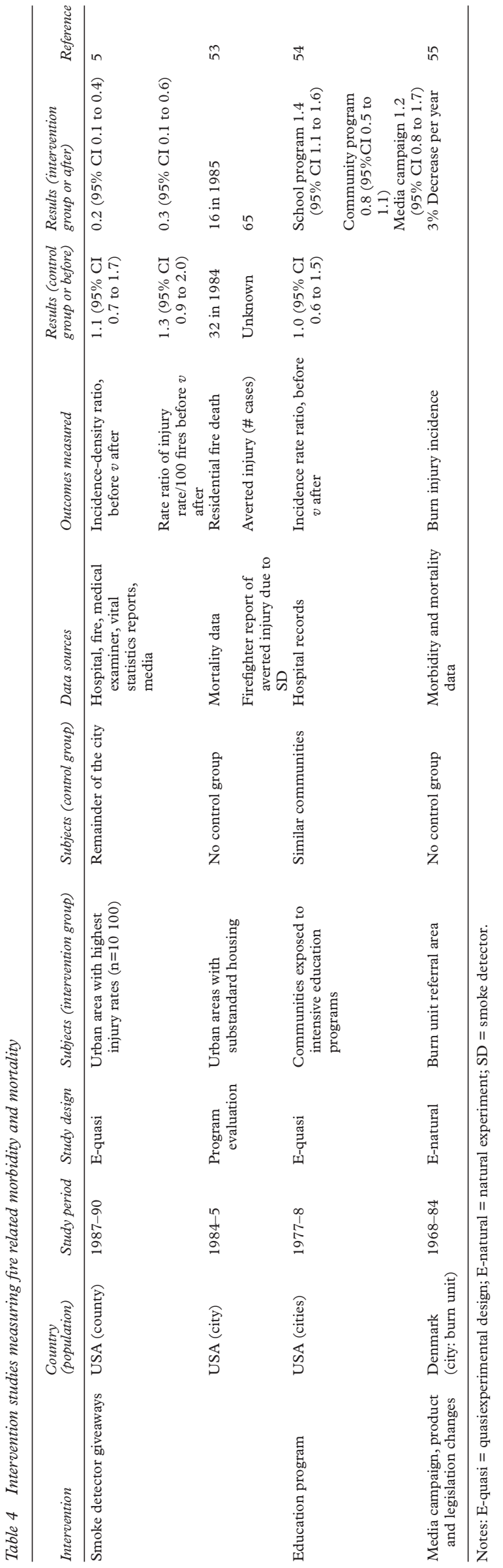

found in the literature, due to cost and time constraints. These studies, however, are limited by a lack of rigor, including lack of control for confounders such as socioeconomic status, ${ }^{5355}$ lack of a control group, ${ }^{5355}$ and inadequate follow up. ${ }^{53}$

\section{Discussion}

This summary of fire and burn prevention interventions highlights some of the successes and limitations of a wide variety of programs that have been implemented and evaluated over the past three decades. Although fire and burn prevention programs are widespread, and a large number of studies have been published that are relevant to program development, the literature lacks a summary of this diverse research. Due to the broad based search strategy used here, a number of effective programs were identified that would have been missed using traditional search methods.

The major limitation of this review pertains to the unavoidable issue of publication bias. However, all relevant data were reported, whether negative or positive, and other sources were used, including a search of research grant databases available on the internet. For practical reasons only English language studies were included, leaving the possibility of language bias. There was also a potential "database bias", towards journals and disciplines indexed on the databases used.

The ranking of studies by design and validity may have been limited by its subjective nature, but a standardized method for indicating the relative strength of studies was desired. There is not a recognized, uniform method of measuring study validity. The method used here allowed a simple summary of how well key study design issues were addressed, and resulted in a rough ranking of studies.

It is unfortunate that only four of the 43 studies examined fire related morbidity and mortality as outcome measures. The results of these four studies were highly variable, due to their varying study design, data sources, and choice of outcome measure. Also contributing to this variability were a lack of control for confounders by some studies, lack of a control group, and inadequate follow up. The use of injury outcomes should be highlighted as a priority for future house fire prevention research.

\section{Implications for prevention}

EDUCATING THE GENERAL PUBLIC

Although pamphlet distribution and poster production have become an accepted part of prevention campaigns, the effectiveness of these potentially expensive tools is unknown. Though the use of mass media information may be desirable, the cost of a truly "marketable" campaign is not practical for most injury prevention organizations. An extensive review of the effects of public communication programs on house fire prevention concluded that no rigorous evidence was available. ${ }^{1}$ Project Burn Prevention, the most recent and rigorous of the studies examining a large scale 
community based campaign using the media, was not effective in reducing burn injury. Nevertheless, the power of the media should not be underestimated; we know that children are highly influenced by television. When elementary schoolchildren in New Zealand were surveyed regarding the source of their fire safety knowledge, between $14 \%$ and $18 \%$ reported television as a source. ${ }^{19}$

SCHOOL BASED EDUCATION PROGRAMS

The review of school based education programs revealed a number of specific methods and components that might improve program effectiveness. Perhaps the most important finding was that programs using active participation by children in learning fire responses were more effective than those using passive methods. This observation is well known to experienced child educators; children enjoy the opportunity to participate, and to rehearse skills, such as "stop, drop, and roll". ${ }^{20-22}$ Similarly, when testing children, actual demonstration of skills is likely a more reliable marker of children's real response in fire situations than providing correct answers on a written test. ${ }^{18} 19$ Training these behavioral responses in small groups of children has resulted in high acquisition of skills in diverse populations, but even these intensive methods are associated with poor long term maintenance of skills. ${ }^{30} 11$ The addition of fear reduction techniques and teaching the rationale supporting the use of correct fire response behaviors may significantly improve skill retention. ${ }^{30}{ }^{33}$ And finally, although small group and behavioral approaches are effective, the application of these techniques on a large scale is impractical. Therefore policy makers may encourage these efforts, but cannot be expected to mandate them.

Several authors noted the need for annual exposure to fire safety training. ${ }^{18} 19$ Periodic repetition of material is required for maintenance of knowledge and skills; however, the format and content of each component or module of a fire and burn prevention program should be tailored according to group size, developmental level, cognitive ability, and actual fire or burn experience. ${ }^{20-22}$ Reinforcement of standardized, hence familiar, fire safety messages could also be provided in the community, such as through the media, or at local fairs or exhibitions. Mascots, such as LNTB's "Sparky", are often used in school programs, and can be used for community based programs as well.

Several authors noted children's positive responses to having figures of authority from the community teach fire safety skills. Three years after the introduction of a large scale firefighter taught program, significantly more children, particularly boys, reported learning fire safety knowledge from a firefighter than before the program. ${ }^{18}{ }^{19}$ Firefighters and burn unit nurses have been involved in numerous programs ${ }^{18} 1921$; this multidisciplinary approach should be encouraged in other school programs.
School based programs can be ineffective for a number of reasons. Schools may not be aware of the availability of resources. Even large scale programs described a problem with lack of exposure and consequent nonparticipation by schools. ${ }^{18} 19$ Some programs are limited by schools choosing not to use the materials provided; others may not use them appropriately. The issue of potential "program overload" should be given careful consideration by injury prevention organizations. Schools may become overwhelmed by the large number of fragmented injury prevention modules, targeting not only fire safety, but also road safety, cycling safety, and head injury prevention.

\section{OFFICE BASED COUNSELING}

Office based counselling programs have documented variable success: one brief intervention was effective, ${ }^{50}$ another more intensive intervention was less effective. ${ }^{45}$ Few studies have examined this issue in detail, and a number of questions remain unanswered. It is not known which component of office based interventions is most effective. Is it the educational materials, personalized advice, or device incentives such as giveaways and coupons? Perhaps focusing effort on a single, simple message, such as purchasing and installing a smoke detector, may be most effective. Addressing multiple hazards may be overwhelming. Does the announced home visit, common to several studies, inspire last minute household adjustments? When should fire safety counselling be provided-at prenatal visits, well baby check-ups, or at any non-acute visit? These questions should be given careful consideration, and may lead to further research.

SMOKE DETECTOR GIVEAWAYS AND PROMOTIONS Smoke detector giveaway programs are appealing, particularly for high risk urban areas, due to their documented success and relatively passive nature. Free smoke detectors provided door-to-door, with immediate assistance with installation, can improve their prevalence substantially. The issue of poor maintenance can limit such programs, however. Batteries are often removed or not replaced, detectors may be inactivated due to false alarms, and those in tenant housing may be vandalized. ${ }^{66}$ Therefore, in certain high risk areas, giveaway programs must be followed by long term maintenance and inspection programs.

REGULATION AND LEGISLATION

Policy makers have played an important part in house fire prevention in many communities across the globe, by mandating smoke detector use in homes, strengthening building codes, improving sleepwear standards, and introducing the child resistant lighter. Some of these initiatives are limited, however, by a lack of enforcement at the community level. Therefore, a coordinated approach involving government, law enforcement, and dedicated community members will be necessary to ensure that fire prevention policy is effective. 
This study was completed during a research fellowship (LW) granted by the Children's Hospital Foundation, Winnipeg,
Manitoba, Canada. Appreciation is expressed to the IM-PACT staff for review of this manuscript.

1 Haskins J. The effects of public communication programs on fire prevention in the home: a review. Washington, DC: Report to the National Commission on Fire Prevention and Control, 1972.

2 McLoughlin E. Issues in evaluation of fire and burn prevention programs. F Burn Care Rehabil 1982;3:281-4

3 McLoughlin E, Vince C, Lee A, et al. Project Burn Prevention: outcome and implications. Am f Public Health 1982;72:241-7.

4 Grant E. Evaluation of a burn prevention program in a public school system. F Burn Care Rehabil 1992;13:703-7.

5 Mallonee S, Istre GR, Rosenberg M, et al. Surveillance and prevention of residential-fire injuries. $N$ Engl $7 \mathrm{Med}$ 1996;335:27-31.

6 Hall J. A decade of detectors: measuring the effect. Fire fournal 1985;78:37-43.

7 Hammond J. The status of statewide burn prevention legislation. F Burn Care Rehabil 1993;14:473-5.

8 Baker SP. The injury fact book. New York: Oxford University Baker SP. The

9 Stanwick RS. Clothing burns in Canadian children. Can Med Assoc F 1985;132:1143-9.

列

1 McGuire A, Daynard RA. When cigarettes start fires: industry liability. Trial 1992;28:44-9.

12 Cope V. Where there's smoking... Attorneys allege tobaccoindustry liability for cigarette fires. Trial 1988;24:42-7.

13 Teret S, DeFrancesco S. The cigarette safety bill: a case study in injury control advocacy. F Public Health Policy 1983;4:440-6.

14 DeFrancesco S, McGuire A. The fire-safe cigarette campaign. F Public Health Policy 1985;6:340-8.

15 Brigham P, McGuire A. Progress towards a fire-safe cigarette. F Public Health Policy 1995;16:433-9.

16 Warda L, Tenenbein M, Moffatt MEK. House fire injury prevention update. Part I. A review of risk factors for fatal and non-fatal house fire injury. Inj Prev 1999;5:145-50.

17 Abramson JH. Survey methods in community medicine: epidemiologic studies, programme evaluation, clinical trials. 4th epidemiologic studies, programme evaluation, clinica

18 Constable C, Renwick M. Children's knowledge of fire safety: what standard 2 children know about fire safety and where they got that information from. Wellington, New Zealand: New Zealand Council for Educational Research, 1993.

19 Dunn K, Renwick M. Children's knowledge of fire safety stage 2: what standard 2 children know about fire safety and where they got that information from. Wellington, New Zealand: New Zealand Council for Educational Research, 1995

20 Morrison M, Herath K, Chase C. Puppets for prevention: "Playing safe is playing smart". F Burn Care Rehabil 1988; 9:650-1.

21 Varas R, Carbone R, Hammond J. A one-hour burn prevention program for grade school children: its approach and success. $\mathcal{F}$ Burn Care Rehabil 1988;9:69-71.

22 Victor J, Lawrence P, Munster A, et al. A statewide targeted burn prevention program. F Burn Care Rehabil 1988;9:4259.

23 Eckelt K, Fannon M, Blades B, et al. A successful burn prevention program in elementary schools. 7 Burn Care Rehavention program in
bil $1985 ; 6: 509-10$.

24 Thompson R, Summers S, Rampey-Dobbs R, et al. The effect of instruction on burn prevention in eighth-grade students in preparation for babysitting. F Burn Care Rehabi 1992;13:482-6.

25 Linares A, Linares H. Burn prevention programmes for children: are they effective? Burns 1979;6:73-9.

26 McConnell C, Leeming F, Dwyer W. Evaluation of a fire-safety training program for preschool children. fournal of Community Psychology 1996;24:213-27.

27 McConnell C, Dwyer W, Leeming F. A behavioral approach to reducing fires in public housing. Fournal of Community Psychology 1996;24:201-12.

28 Katz R, Singh N. Comprehensive fire-safety training for adult mentally retarded persons. Fournal of Mental Deficiency Research 1986;30:59-69.

29 Thomas K, Hassanein R, Christophersen E. Evaluation of group well-child care for improving burn prevention pracgroup well-child care for improving burn pre
tices in the home. Pediatrics $1984 ; 74: 879-82$.

30 Williams C, Jones R. Impact of self-instructions on response maintenance and children's fear of fire. Fournal of Clinical Child Psychology 1989;18:84-9.
31 Jones R, Haney J. Refinement of a primary preventive approach to fire emergencies: a comparison of external and self-instruction strategies for training and maintaining fire emergency responding. Pittsburgh, PA: University of Pittsburgh, 1983.

32 Mori L, Peterson L. Training preschoolers in home safety skills to prevent inadvertent injury. Fournal of Clinical Child Psychology 1986;15:106-14.

33 Hillman H, Jones R, Farmer L. The acquisition and maintenance of fire emergency skills: effects of rationale and behavioral practice. F Pediatr Psychol 1986;11:247-58.

34 Jones R, Ollendick T, McLaughlin K, et al. Elaborative and behavioral rehearsal in the acquisition of fire emergency skills and the reduction of fear of fire. Behavior Therapy 1989;20:93-101.

35 Jones R, Kazdin A, Haney J. Social validation and training of emergency fire safety skills for potential injury prevention and life saving. $\mathcal{F}$ Appl Behav Anal 1981;14:249-60.

36 Peterson L. The "Safe at home" game: training comprehensive prevention skills in latchkey children. Behav Modif 1984;8:474-94.

37 Jones R, Van Hasselt V, Sisson L. Emergency fire-safety skills: a study with blind adolescents. Behav Modif 1984;8: $59-78$.

38 Jones R, Sisson L, Van Hasselt V. Emergency fire-safety skills for blind children and adolescents: group training and generalization. Behav Modif 1984;8:267-86.

39 Rowe M, Kedesdy J. Fire evacuation skills training for institutionalized mentally retarded adults. Behavioral Residential Treatment 1988;3:101-18.

40 Holburn C, Dougher M. The fire-alarm game: exit training using negative and positive reinforcement under varied stimulus conditions. Fournal of Visual Impairment and Blindness 1985;79:401-3

41 Haney J, Jones R. Programming maintenance as a major component of a community-centered prevetive effort: escape from fire. Behavior Therapy 1982;13:47-62.

42 Jones $\mathrm{R}$, Thornton J. The acquisition and maintenance of emergency evacuation skills with mildly to moderately retarded adults in a community living arrangement. Fournal of Community Psychology 1987;15:205-15.

43 Rae R, Roll D. Fire safety training with adults who are profoundly mentally retarded. Ment Retard 1985;23:26-30.

44 Dershewitz R, Williamson J. Prevention of childhood household injuries: a controlled clinical trial. Am f Public Health 1977;67:1148-53.

45 Kelly B, Sein C, McCarthy P. Safety education in a pediatric primary care setting. Pediatrics 1987;79:818-24.

46 Gallagher S, Hunter P, Guyer B. A home injury prevention program for children. Pediatr Clin North Am 1985;32:95112 .

47 Schwarz D, Grisso J, Miles C, et al. An injury prevention program in an urban African-American community. $A m \mathcal{F}$ Public Health 1993;83:675-80.

48 Bablouzian L, Freedman E, Wolski K, et al. Evaluation of a community based childhood injury prevention program. Inj Prev 1997;3:14-6.

49 Schmeer S, Stern N, Monafo W. An outreach burn prevention program for home care patients. F Burn Care Rehabil $1988 ; 9: 645-7$.

50 Miller RE, Reisinger KS, Blatter MM, et al. Pediatric counseling and subsequent use of smoke detectors. Am F Public Health 1982;72:392-3.

51 Gorman R, Charney E, Holtzman N, et al. A successful citywide smoke detector giveaway program. Pediatrics $1985 ; 75$ : 14-18.

52 McLoughlin E, Marchone M, Hanger S, et al. Smoke detector legislation: its effect on owner-occupied homes. Am $\mathcal{F}$ Public Health 1985;75:858-62.

53 Schmeer S, Stern N, Monafo W. An effective burn prevention program initiated by a recovered burn patient group. 7 Burn Care Rehabil 1986;7:535-6.

54 MacKay A, Rothman K. The incidence and severity of burn injuries following Project Burn Prevention. Am f Public Health 1982;72:248-52.

55 Elberg J, Schroder H, Glent-Madsen L, et al. Burns: epidemiology and the effect of a prevention program. Burns 1987;13:391-3.

56 Hall J. The US experience with smoke detectors: who has them? How well do they work? When don't they work? National Fire Protection Association fournal 1994; September/October:36-46. 